\title{
Los «malos usos» y la reglamentación de los temascales públicos mexicanos (1686-1691)¹
}

\section{The «misuse» of public mexican temascales (1686-1691)}

\section{Patricio Hidalgo Nuchera}

Universidad Autónoma de Madrid

La llegada del conde de Galve a México como virrey de la Nueva España supuso la puesta en marcha de toda una serie de medidas dirigidas a conseguir la regeneración moral de la sociedad novohispana. Objetivos de su atención fueron, entre otros, el pulque, el baratillo, la delincuencia y lo que él entendía como ineficacia de la sala del crimen. En este trabajo enfocaremos nuestra atención en los temascales o baños de vapor, muy concurridos en la capital novohispana debido a sus funciones sociales, higiénicas y terapéuticas, entre ellas las de ayuda al parto. Sin embargo, la introducción de una serie de «malos usos»llevó primero al conde de la Monclova (1686-1688) y, luego, a su sucesor el conde de Galve (1688-1696) a reglamentar su funcionamiento.

Palabras Clave: Temascal; Baños de vapor; Pecado nefando; Informes médicos.

The arrival of the Count of Galve in Mexico as Viceroy of New Spain marked the start of a new series of measures aimed at achieving the moral regeneration of the New Spanish society. Among others, the targets of the measures were pulque (a Mexican alcoholic drink), baratillo (a flea market), crime and, in the Count's view, the ineffectiveness of the Court of Law (sala del crimen). In this paper we focus on temascales, which were public steam bathrooms widely used in the capital city because of their social, sanitary, and medical functions, such as pain relief during labor. However, the increasing 'misuse' of these bathrooms forced the Count of Galve (1686-1688) first, and his heir the Count of Galve (1688-1696) later on, to regulate their use.

KEYwORDS: Temascal; Steam bathrooms; Sodomy; Medical reports. siglo XVII.

1 Este trabajo es parte de una investigación en curso sobre la sociedad novohispana a fines del 


\section{Estructura y función de los baños de vapor}

Los temascales — palabra derivada del náhuatl temazcalli, que significa «casa de baño»— eran baños de vapor cuyo origen se remonta a las culturas prehispánicas de Mesoamérica. El antropólogo Alcina Franch ha estudiado exhaustivamente tanto sus estructuras como sus usos y significados. En cuanto a las primeras, el temascal consta de una cámara central o sala de vapor, donde tiene lugar el baño, y de un hornillo o lugar donde se produce el fuego a partir del cual se obtendrá el vapor de agua. Este hornillo podía ser una construcción bien anexa a la sala de vapor, bien incluida en ella, aunque en ocasiones era una zona en el interior del temascal que se dedicaba a servir de hogar, sin que hubiese separación alguna del resto de la sala de vapor; en este último caso, una abertura servía tanto para alimentar el fuego con más madera como para animarlo mediante la corriente de aire que se establecía con un pequeño vano o respiradero que servía para que la sala de vapor quedase limpia de humos antes de que entrasen los bañistas.

Otros elementos del temascal eran una puerta, que solía ser tan pequeña que había que entrar a la sala de vapor arrastrándose de rodillas; y un desagüe que permitía expulsar del interior de la sala el agua sobrante de la empleada tanto para producir vapor como para echarla directamente sobre el cuerpo. Por último, uno o varios bancos servían a los bañistas como lugar para recostarse y descansar. En cuanto al sistema para obtener el vapor de agua, si el hornillo o fogón estaba situado en el exterior del baño, el fuego calentaba la pared recayente a la sala de vapor y sobre la que se arrojaba agua para provocar el vapor; también era frecuente el procedimiento consistente en calentar piedras o tiestos de cerámica sobre los que se vertía el agua para generar vapor.

La tipología de los temascales era muy variada. Los había de planta rectangular, cuadrada o circular; la construcción estaba a veces sobre el terreno, otras era semisubterránea o enteramente subterránea; el techo podía ser a dos aguas, plano o cupuliforme. El tamaño variaba desde los que servían para una o dos personas hasta los que permitían la entrada de hasta veinte o treinta personas. Y en cuanto a los materiales de construcción, para los muros se utilizaba el barro y la piedra, sobre todo la pómez o de tezontle, aunque la parte interior podía presentar un enlucido más o menos fino. El pavimento solía ser de tierra apisonada, aunque los había enlosados y de ladrillo. Y finalmente, la techumbre solía ser de piedra y barro sobre armazón de madera. 
En los tiempos prehispánicos, antes de construir un baño se hacían ofrendas a los dioses del temascal y se enterraba un idolillo en el lugar donde se iba a levantar para así proteger al temascal; en la colonia, el sacerdote lo bendecía, síntoma de que no perdió el carácter sagrado que antiguamente tenía. ${ }^{2}$

Silva Galeana ha transcrito un texto náhuatl que describe el rito del baño. En él se relata que, antes de entrar el bañista, se encendía la hornilla y se calentaba agua junto a ella; cuando el temascal se hallaba caliente, se tapaba la hornilla con una piedra plana de tezontle y se arrojaba el agua caliente sobre ella, produciéndose el vapor; a continuación se esparcía grama y, finalmente, entraba el bañista, llevando consigo hierbas, generalmente aromáticas, tanto para atraer hacia sí el vapor como para golpearse suavemente el cuerpo con ellas. ${ }^{3}$

¿Qué funciones tenía el baño de vapor? Alcina Franch señala cuatro en concreto: higiene, relaciones sociales, terapéutica y partos; mientras las dos primeras son funciones de tipo social, las dos últimas — controladas por médicos, comadronas, parteras, etc.—- son más específicamente religiosas. ${ }^{4} \mathrm{~A}$ destacar el uso que de los baños hacían las mujeres embarazadas, a las que se les practicaban masajes con el fin de relajarlas tanto antes como después del parto. También los usaban los enfermos, quienes se recostaban sobre un petate o estera mientras un acompañante les golpeaba con suavidad la parte enferma del cuerpo con un manojo de hierbas. ${ }^{5}$ Sin duda, el temascal era el sitio de purificación por excelencia, acto entendido como expulsar del cuerpo las sustancias que le podrían enfermar. De ahí que Alcina Franch considere al temazcalli como un instrumento de higiene corporal y de purificación espiritual. ${ }^{6}$

Además de las funciones señaladas, el temascal era también usado como lugar de encuentro para el mantenimiento de furtivas relaciones sexuales entre personas de igual o distinto sexo. Así lo declara explícitamente el citado texto traducido del náhuatl por Silva Galeana:

También se dice que, cuando hombres y mujeres se van ahí a 'hacer algo' secretamente, quienes después se bañan 'sobre ellos se hace la obscuridad' (se desmayan), se

2 Alcina Franch, 1992, 131-161. Este trabajo se completa con una amplia bibliografía y una serie de planos de distintos temascales.

3 Silva Galeana, 1984, 227-233. Véase, asimismo, Soustelle, 1956, 135-136.

4 Alcina Franch, 2000, 29.

5 Viesca, 1986, 165.

6 Alcina Franch, 2000, 29. 
quedan dormidos, y cuando despiertan les duele la cabeza. Esto demuestra que allá fueron antes algunos a hacer 'su porquería', que allá fueron a darse placer.

Un texto de principios de 1687 nos informa, por último, sobre qué eran los temascales, su uso, número y horario de apertura en plena época colonial:

[...] se halló que hay en México más de cien temascales públicos, sin otros muchos particulares que tienen en sus casas algunos vecinos como una costumbre introducida de muchos años a esta parte, sin que se pueda hallar el origen y principio y el fin y el motivo de su introducción. Los temascales son, unos subterráneos, otros sobre el haz de la tierra, en forma de hornos largos y anchos y muy bajos de techo, de cosa de vara y media poco más o menos, donde con fuego se calientan y con otros fomentos, azotes, movimientos y aspersiones de poca agua en las paredes calientes con exceso se procura sudar, y las personas que dentro de él están que, como va referido, son hombres y mujeres desnudos y de todos estados y calidades, salen y entran dos y tres veces a lavarse, unos con agua fría y otros con caliente, conservándose en tan grande indecencia no sólo cuando están dentro del temascal sino también cuando está fuera a vista y publicidad de todos, fomentando semejante deshonestidad con diferentes cantares, provocando la lujuria, y de ordinario dura desde las dos de la tarde, a cuya hora encienden todos los días los temascales, hasta media noche. ${ }^{8}$

\section{Los «malos usos» de los temascales públicos}

A fines de 1686 o principios del año siguiente alguien, movido bien por el decoro moral, bien por la envidia o simplemente por celos, denunció que en un temascal de la ciudad de México se había cometido el pecado nefando. Detenidos los «delincuentes» - como apostrofa la documentación al mulato Santiago de Quesada y al indio Diego Sánchez-, se probó tanto la sodomía de los citados como que en el propio baño, junto a los detenidos, había siete mujeres más — una española cachupina, una negra, dos mestizas y tres indias-, todos en cueros tomando los vapores. ${ }^{9}$

A raíz de esta denuncia, la sala del crimen encargó a uno de sus miembros, el alcalde don Fernando de Haro y Monterroso, la averiguación de lo que ocurría en los temascales. Durante los días 9 y 10 de enero de 1687, seis receptores acompañados de ministros visitaron diversos baños con la orden de detener a sus dueños o personas que estuvieran al frente de ellos si hallaban hombres y mujeres bañándose juntos. Los temascales abiertos visitados fueron los siguientes:

7 Silva Galeana, 1984, 231.

8 Archivo General de Indias (AGI), México, 87, consulta de la sala del crimen al virrey, México, 22 de enero de 1687.

9 Ibidem. Sobre la homosexualidad en la época, ver Gruzinski, 1985, 255-279. 


\section{CUADRO I}

\section{DUEÑOS DE TEMASCALES PÚBLICOS EN LA CIUDAD DE MÉXICO EN ENERO DE $1687^{10}$}

\begin{tabular}{|c|c|c|c|}
\hline Núm. & Nombre & Calidad & Barrio o lugar \\
\hline 1 & Agustina de la Cruz ${ }^{11}$ & India & San Pablo \\
\hline 2 & Antonia de Cárdenas ${ }^{12}$ & No dice & $\begin{array}{l}\text { Calle de la puerta falsa del } \\
\text { convento de Santo Domingo }\end{array}$ \\
\hline 3 & Antonio de Santa María & Indio & Concepción \\
\hline 4 & Baño que llaman de Solano & No dice & Santa Cruz \\
\hline 5 & Catarina de la Cruz & India & San Juan \\
\hline 6 & Domingo de la Cruz ${ }^{13}$ & Indio & Placeta de San Pablo que cae al rastro \\
\hline 7 & Francisca Jerónima & India & San Juan \\
\hline 8 & Francisco de Santiago & Indio & Rancho de San Diego \\
\hline 9 & Josefa de la Encarnación & Mestiza & Frente a San Lorenzo \\
\hline 10 & Josefa de Santisteban ${ }^{14}$ & No dice & Curtidores \\
\hline 11 & Josefa María & India & Del Hornillo \\
\hline 12 & Juan Andrés & Indio & Del Rastro \\
\hline 13 & Juan Marcos & Indio & Necatitlan \\
\hline 14 & Juan Mateo & Indio & Puente del Espíritu Santo \\
\hline 15 & Juana «la temascalera» & No dice & Puente del clérigo \\
\hline 16 & Juana de la Cruz & India & La Merced \\
\hline 17 & Juana Jerónima & India & La Alameda \\
\hline 18 & María Antonia & Mulata & Chiconautla \\
\hline 19 & María Antonia $^{15}$ & Mulata & El Carmen \\
\hline 20 & María Luisa & India & Santa Caterina \\
\hline 21 & Nicolasa María & India & Calle del Águila \\
\hline 22 & Sebastián de Cepeda & Español & San Juan \\
\hline 23 & Sebastiana de la Cruz & India & Calle cerrada de Santo Domingo \\
\hline
\end{tabular}

10 Ibidem, de oficio de la real justicia contra los temascales, a que concurren hombres y mujeres bañándose juntos. Acompaña a la carta de la sala del crimen al rey, México, 11 de agosto de 1687. Los temascales listados no eran todos los existentes, sino sólo los abiertos. En efecto, el receptor que visitó el barrio de Santiago señala que «habiendo entrado en diferentes temascales que se me mostraron, se hallaron los más cerrados».

11 Lo tenía a su cuidado.

12 Estaba al cuidado de la india Inés Sebastiana.

13 Era arrendatario del baño.

14 Lo tenía arrendado a Diego Martínez y cuidaba de él, en el momento de la visita del receptor de la sala del crimen, la india Nicolasa de los Ángeles.

15 Cuando el receptor visitó este baño el 10 de enero de 1687, su dueña - la mulata María Antonia - ya había sido detenida por un primer visitador; sin embargo, la documentación no recoge esta diligencia y sí la prisión el mismo día de una persona de igual nombre y calidad dueña de un temascal situado en el barrio de Chiconautla. ¿Podría tratarse de la misma persona y del mismo baño? 
En todos ellos hallaron hombres y mujeres de todas las calidades -indios, mestizos, mulatos y españoles- bañándose juntos y desnudos, por lo que fueron detenidos tanto las personas que en ese momento estaban al cuidado de los baños como algunos de los bañistas. Para los magistrados, aquello era un desorden moral que conducía a deshonestidades, incestos, adulterios y otros vicios abominables, además de ser pernicioso, ofensivo a Dios y a la república. Además de pecados — trasgresión de normas o preceptos religiosos-, eran delitos morales perseguidos por la ley, ya que entonces delito y pecado eran una misma cosa y, como señala Bartolomé Clavero, el Derecho más que la vida protegía el alma. ${ }^{16}$ Por todo ello y con el fin de que cesasen tales inmoralidades, los miembros de la sala del crimen no dudaron en ordenar, por auto de 11 de enero de 1687, que se comunicase a los dueños de los temascales que no los encendiesen hasta contar con una licencia del virrey bajo la pena de doscientos azotes; y, por otra parte, se determinó que las personas detenidas fueran puestas en libertad abonando dos pesos cada una y que, quien no los tuviese, fuese conducido a un obraje. ${ }^{17}$ Tan sólo dos de las personas detenidas en las visitas a los baños fueron juzgadas. ${ }^{18}$

El conde de la Monclova se vio en un dilema, ya que aprobar el auto de la sala de cerrar los baños podría ser una medida que disgustara a los sectores populares y engendrara un peligroso malestar. De ahí que, amparándose en que la materia era de gobierno, decretó que todos aquellos que tuvieran temascales los siguieran usando hasta nueva orden, eso sí, apercibiendo a los dueños que serían severamente castigados si en ellos se cometían delitos y si hombres y mujeres entraban juntos a bañarse en ellos. ${ }^{19} \mathrm{La}$

16 Clavero, 1990, 63 y 88.

17 AGI, México, 87, auto de la sala del crimen, México, 11 de enero de 1687. En dicho auto se citan los nombres de los dos hombres prendidos por practicar el pecado nefando, el mulato Santiago de Quesada y el indio Diego Sánchez, afirmando que todavía no habían sido juzgados.

18 Ibidem, se trata del indio Juan Gabriel, acusado de estar amancebado con una india casada. En su declaración del 10 de enero de 1687, la acusada, de quien se omite el nombre por estar casada, confesó que desde hacía un mes mantenía relaciones ilícitas con Juan Gabriel; en cambio, éste, también casado y de oficio botonero, lo negó rotundamente, declarando que él iba paseando por la calle de la Compañía cuando le llamó una india desde el zaguán de un temascal situado en la calle de San Pedro y San Pablo; entró a hablar con ella, momento en que pasó un ministro y lo detuvo. Palabra contra palabra, los ministros de la sala del crimen dictaminaron el 17 de enero que debía apercibirse al indio de que, bajo pena de cuatro años de obraje, no viese más a la acusada y que pagando seis pesos fuese puesto en libertad, aunque si no los tuviere debería ser conducido a un obraje hasta haberlos satisfecho.

19 AGI, México, 58, decreto del conde de la Monclova, México, 15 de enero de 1687. En testimonio de lo determinado en conformidad de la real cédula de S. M. sobre la prohibición de los temascales y el orden que se dio para los doce que han de quedar en la ciudad de México. Acompaña a la carta del conde de Galve al rey, México, 7 de diciembre de 1689. 
medida fue notificada al día siguiente a los propietarios o encargados de temascales que listamos a continuación.

\section{CuAdro II}

\section{DUEÑOS DE TEMASCALES PÚBLICOS EN LA CIUDAD DE MÉXICO EN ENERO DE $1689^{20}$}

\begin{tabular}{rlll} 
Núm. & \multicolumn{1}{c}{ Nombre } & Calidad & \multicolumn{1}{c}{ Barrio o lugar } \\
\hline 1 & Ana de Esquivel & Española & San Pablo \\
2 & Antonio de Santa María & Indio & La Concepción \\
3 & Antonio Solano & Español & La Merced \\
4 & Doña Ana de la Llana & Española & El Carmen \\
5 & Doña Josefa de Santisteban & Española & San Pablo \\
6 & Doña María de Castro & Española & Santo Domingo \\
7 & Francisca Romero & Española & Del Rastro y en el de Belén \\
8 & Francisco de Olvera & Indio & Puente del Clérigo \\
9 & Gabriel de la Barrera & Español & N. ${ }^{a}$ S. ${ }^{a}$ de la Candelaria \\
10 & José de la Barreda & Español & San Diego \\
11 & Josefa de la Encarnación & Mestiza & San Lorenzo \\
12 & Josefa María & India & Del Hornillo \\
13 & Juan de Campos & Español & Del Rastro y en el de Belén \\
14 & Juan de Guerrero Lobo & Español & La Merced \\
15 & Juan Mateo & Indio & Puente del Hospital del Espíritu Santo \\
16 & Juana Jerónima & India & San Diego \\
17 & Luisa de la Cruz & & \\
& y M. ${ }^{a}$ de la Concepción & Indias & San Sibrián [sic] \\
18 & Miguel de los Ángeles & Indio & San Pablo \\
19 & Miguel García & Mulato & Lagunilla \\
20 & Nicolasa María & No dice & Santiago \\
21 & Petronila de Nava & Mulata & Chiconautla \\
22 & Sebastiana de la Cruz & India & Santo Domingo
\end{tabular}

La sala del crimen, disconforme con la medida del conde de la Monclova, a pesar de que éste la justificó en el mantenimiento del orden público, pasó a realizar tres movimientos consecutivos: solicitar un informe médico sobre la virtud terapéutica de los baños, consultar al virrey y, por último, escribir a Madrid. En cuanto al primero, sus firmantes - los doctores José Díaz Brisuela, Antonio de Córdoba, Francisco Antonio Jiménez y Juan de Escobar y Soltero, el bachiller Diego de Lodosa y el

20 Ibidem, testimonio de lo determinado en conformidad. 
maestro Luis de Molina- dieron la razón a los alcaldes del crimen al declarar que

En cumplimiento de la orden de vuesa merced, decimos que los temascales no son necesarios a la conservación de la vida humana, antes bien, son nocivos y causa de grandes enfermedades. Y en los indios se han experimentado diferentes dolencias originadas del uso de los temascales. Y aunque para alguna enfermedad pueden ser provechosos, hay en la medicina muchos remedios con que se pueda ocurrir al doliente sin usar de éste. Es nuestro sentir, salvo etc. México, 18 de enero de $1687 .{ }^{21}$

Como puede comprobarse en la transcripción realizada, los doctores omitieron los fundamentos en que basaban su opinión porque nadie se los había pedido. No es de extrañar, por tanto, la parcialidad del informe, favorable a los intereses de quienes lo habían solicitado.

El segundo movimiento de los alcaldes del crimen fue elevar una consulta al conde de la Monclova con fecha de 22 de enero de 1687. Tras aludir a los acontecimientos ya citados, los alcaldes del crimen confesaban que, aunque ellos pudieran cerrar los temascales por competerles el castigar y corregir los pecados públicos, no lo habían hecho tanto por respeto al virrey como

[...] por ser materia nueva y muy sensible así a los dueños de los temascales, que tienen sus intereses por lo que perciben de los arrendamientos de ellos, y hay convento de monjas que tienen tres que dan en arrendamiento, frailes, clérigos, caballeros y otras personas de su posición, como a todo el vulgo de esta numerosísima ciudad que están acostumbrados a este diabólico vicio con unas raíces muy hondas, y se les ha de causar gran sentimiento el que se les quite este fundamento de pecados. ${ }^{22}$

Para la sala, hacía falta toda la autoridad del virrey para aniquilar a lo que ellos llamaban «ídolo» porque arrastraba a los hombres al pecado. Para llevarlo a cabo, los alcaldes del crimen consultaban al virrey la adopción de las tres siguientes medidas: que ninguna persona usase los temascales, tanto los mixtos como los reservados exclusivamente a un solo género, bajo ningún pretexto, aunque fuese médico, so pena de doscientos azotes y diez años de obraje si los usuarios o encargados de encenderlos fuesen indios, mestizos y mulatos, y diez años de Filipinas si fueran españoles; que se derribasen todos los baños de vapor; y por último, que los alcaldes mayo-

21 AGI, México, 87, parecer de los médicos, México, 18 de enero de 1687. de 1687 .

22 Ibidem, consulta de la sala del crimen al conde de la Monclova, México, 22 de enero 
res fuesen los encargados de llevar a cabo lo anterior, haciéndoles cargo en sus residencias si lo incumpliesen. Los miembros de la sala del crimen fundamentaban su radical propuesta en la promiscuidad pecaminosa existente en los baños, en la oportunidad que ofrecían tanto a hombres como a mujeres para cometer actos homosexuales y, finalmente, en el informe médico antes citado que desmentía los efectos benéficos de los baños. Finalizaban con la opinión de que:

Todo lo referido se convence que el uso de los temascales es intrínsecamente malo, pecaminoso, con circunstancias tan agravantes, sirviendo solamente para fomento de vicios y pecados y que no conducen para la conservación de la salud, antes son dañosos a ella y ocasionan muchas enfermedades, y cuando pudieran aprovechar para algún achaque particular hay muchos medicamentos que lo pueden suplir, y en caso que no los hubiera no se deben aplicar medios pecaminosos para conseguir la salud del cuerpo, y así se deben quitar absolutamente para que no se desvíe de ellos con ningún pretexto, debajo de las penas que quedan referidas o las que a vuesa excelencia pareciere. ${ }^{23}$

Tras elevar esta consulta al virrey, el tercer movimiento de los alcaldes del crimen respecto a los temascales fue escribir a Madrid, dando cuenta de todo lo efectuado hasta el momento. Y aunque afirmaban estar seguros de que el virrey los cerraría, les debió de quedar alguna duda cuando solicitaban al monarca su prohibición absoluta, atendiendo a que era «materia abominable propia de bárbaros y muy ajena de república cristiana, y que conviene se prohíba sin que quede puerta ni resquicio de volverse otra vez a introducir con pretexto de la salud corporal». ${ }^{24}$

En la corte la petición de los alcaldes del crimen de la Audiencia de México fue informada positivamente por el fiscal del Consejo de Indias el 21 de febrero de 1688, aprobada por ese organismo el 5 de abril y hecha saber al conde de la Monclova mediante la real cédula fechada en Madrid a 14 de agosto del mismo año. Fue una desautorización al virrey, quien, como hemos visto, decidió conservarlos —al decir de su sucesor el conde de Galve- «con ciertas limitaciones por resultar lo contrario en detrimento grave de la causa y seguridad pública». ${ }^{25}$

El despacho real prohibiendo totalmente los temascales llegó a México cuando había un nuevo gobernante al frente del virreinato, el cita-

\footnotetext{
23 Ibidem.

24 Ibidem. Sala del crimen al rey, México, 11 de agosto de 1687.

25 AGI, México, 58, conde de Galve al rey, México, 7 de diciembre de 1689.
} 
do conde de Galve. Sin duda que, previendo el malestar social que causaría la medida, el nuevo virrey decidió por decreto de 8 de octubre de 1689 llevarla al real acuerdo, el cual en su posterior informe hizo la distinción entre temascales privados y públicos. En cuanto a los primeros, o sea, los que cada indio tuviera para sí y su familia, se debían permitir en razón del alivio que proporcionaban, eso sí, observando el recato y modestia cristiana y evitando el concurso en ellos de dos personas a la vez; y en cuanto a los públicos, el real acuerdo sugirió que se restringiesen a doce, seis para hombres y otros seis para mujeres, con la condición de que a ellos, aparte de la mentada separación de sexos, entrasen sus clientes siempre solos. El resto de los baños debían desaparecer, castigándose a su propietario con doscientos azotes y diez años de obraje si fuera indio y sólo con destierro a Filipinas u otro presidio si era de «otra esfera»; en ambos casos, además del castigo, el temascal sería demolido. ${ }^{26}$

Empero, el virrey no se conformó con este informe y, con el fin de tener mayores datos sobre los que basar su decisión, solicitó el de dos médicos sobre los siguientes aspectos: si los temascales eran medicinales, qué uso había que hacer de ellos, qué tipo de gente podía usarlos y si de su prohibición se seguirían daños irreparables.

\section{Los informes médicos de 1689}

Los informes fueron solicitados a los doctores Ambrosio de la Lima y José de Oliver, quienes los presentaron el 29 de octubre y el 2 de noviembre de 1689 respectivamente. Aunque el primero es más prolijo, ambos coincidían en ser los baños saludables y preservativos de la salud, a la vez que muy perniciosa su falta. ${ }^{27}$ Todo lo opuesto, pues, al informe médico evacuado el 18 de enero de 1687 a solicitud de los alcaldes del crimen, lo que demuestra que las respuestas siempre están sesgadas a favor de los intereses de quienes las solicitan. El informe del doctor Oliver responde de manera muy precisa a las cuestiones planteadas por el virrey:

1. Afirma que los baños no sólo son medicinales sino también útiles y necesarios para que la gente pobre, sudando en ellos, viva en limpieza, conserve la salud, alargue la vida y sane de males que los baños preservan.

26 Ibidem, testimonio incluido en nota 19, que acompaña a la carta citada en nota anterior.

27 Ibidem. Los informes están transcritos en Silva Prada, 2002, 5-56. 
2. ${ }^{\circ}$ Defiende que si los baños son útiles para los indios también lo serán para el resto de las razas que habitan México, excepto para los españoles, ya que éstos son «de más adusto temperamento, más ardientes hígados y, la mayoría de ellos, los más catarrosos y destemplados de la cabeza».

3. Aunque las autoridades médicas prescriben diversas reglas para el uso de los baños, niega que puedan aplicarse a los indios, quienes no sólo las desprecian sino que ello no tiene consecuencias negativas para ellos.

4. ${ }^{\circ}$ Finalmente, opina que de la prohibición de los temascales se seguirían muchos males a los indios, tales como privarles del descanso que hallan bañándose después del infatigable trabajo que realizaban; carecerían de limpieza, con la que viven más sanos; no tendrían el alivio que se les sigue con sólo sudar, hallándose repletos de perversos humores y enfermedades; y por último, «quedarían destruidos del remedio preservativo y curativo de todas las enfermedades que padecen, pues en ellos el baño es un remedio fácil y eficaz, sin más coste que el de entrar a sudar en un temascal». ${ }^{28}$

Aparte de estas consideraciones médicas y aunque no se le pidió, el doctor Oliver ofrece su opinión sobre los inconvenientes morales de los temascales. Para él la solución es bien fácil: implantar en México los mismos remedios que ya establecieron algunos emperadores romanos, tales como cerrar los baños durante la noche y prohibir la concurrencia de hombres y mujeres en unas mismas instalaciones.

Por su parte, el informe del doctor Ambrosio de la Lima es más extenso y está salpicado constantemente de citas de autoridades clásicas. Su primera intención es probar la antigüedad y uso universal de los baños, lo cual realiza citando pasajes de la Biblia y autores como Galeno, Celsio Rodiginio, Juan Bautista Egano y Justino. A continuación, prueba la identidad de las termas romanas con los temascales indios, resultando muy interesante este punto puesto que nos ofrece nueva información sobre los últimos. Basándose en autores como Calepino y Galeno, describe las termas romanas como la sucesión de cuatro estancias: en la primera había aire caliente, en la segunda agua caliente, en la tercera agua fría y, por último, una dedicada a que los bañistas se ungieran. En cambio, el temascal es:

un aposento pequeño lleno de aire caliente. Tiene forma de bóveda y una puerta pequeña por donde entrar. Entran en este aposento el cuerpo y dejan las cabezas hacia la puerta libres para respirar aire templado. Por la parte posterior está otra ventanita muy

28 Ibidem. 
pequeña por la cual entra el aire caliente a que dan fuego con artificioso primor, pues entra un vapor de agua que está en un vaso u olla que se calienta al calor del fuego, con que ellos no participan del fuego; después de esto, salidos del aposento pequeño, se echan agua fría. Esto se entiende en los sanos, que los enfermos se retiran a sudar. No gastan más ungüentos y todo esto se reduce a salir del hipocausto y echarse agua fría. Lo mismo eran las termas. No sé yo qué se pueda decir con más claridad. ${ }^{29}$

Probada la antigüedad de los baños y la identidad de termas romanas y temascales mesoamericanos, el doctor De la Lima pasa a probar la utilidad de los baños. Su silogismo es claro: si las termas, según Galeno, curaban a los héticos (personas flacas y casi en los huesos) y termas y temascales eran lo mismo, luego éstos últimos también curaban a los héticos, aunque de una manera más suave, ya que en ellos los bañistas únicamente pasaban del agua caliente a la fría. Además, el doctor mexicano argumentaba la utilidad de los baños en el hecho de que naciones tan guerreras como los agarenos, los turcos y los romanos los usaban tal como hacían los indios, quienes, aunque más pacíficos, les aventajaban a todos ellos en trabajo, a lo que habría que sumar el que se abrigaban poco, cargaban hasta ocho arrobas de peso sobre sus espaldas, cambiaban continuamente de temples, no les salían canas tan temprano, se bañaban tres o cuatro veces a la semana y las mujeres iban a los temascales al tercer o cuarto día después de parir. La utilidad estaba, pues, bien clara para la conservación de la salud y el doctor Ambrosio de la Lima los aconsejaba incluso al resto de la población mexicana.

A ello habría que sumar las propiedades preservativas y curativas de las aguas. Frente a los autores clásicos que ensalzaban el valor de las aguas venecianas, las del Nilo o las de Haspa, el doctor De la Lima hace lo mismo con las siguientes de Nueva España: los baños de Atotonilco, cerca de Pachuca, los de Araron en Michoacán, los de Ixtlaclala (sic), que tienen gran virtud para sanar úlceras envejecidas y ya tratadas por médicos y cirujanos; los del Peñol, a una milla de México, que tienen admirable eficacia para remover los impedimentos de la reproducción «y hubiera sido lástima extirparlos porque se hubieran malogrado sucesiones ilustres», ${ }^{30} \mathrm{y}$, por último, cita los baños del marqués del Valle en la provincia de Amilpas, que aunque no sirven para curar sí para recreo y deleite. En su informe, el doctor De la Lima responde, además, a diversas críticas que se hacían a los temascales. 
1. ${ }^{\text {a }}$ crítica: que los indios se azotaban en ellos. Tras afirmar que los espartanos azotaban a sus hijos regularmente para ejercitarlos en la paciencia y el sufrimiento y que para la Iglesia la disciplina era el remedio para mortificar los apetitos, el doctor niega que los indios se azotasen ni hiriesen sus cuerpos, sino que sólo se abanicaban con las hojas de maíz que cubrían los temascales.

2. ${ }^{\text {a }}$ crítica: que los temascales eran sudatorios. Tras exponer que los aposentos calientes de las termas también lo eran, el doctor comenta que, según Galeno, el aire caliente abre los poros y facilita que el cuerpo expulse de sí los hálitos y recrementos, ${ }^{31}$ mientras que el agua fría consolida y fortalece la carne. Por tanto, para De la Lima el sudor era la cosa más útil y provechosa para la conservación de la salud. También critica a los que piensan que una exudación continuada podía «exolver», o sea, disolver, el calor natural de los cuerpos; si esto fuera así, responde, la canícula y las tierras calientes serían reprehensibles, y que si los baños «exolvieran» todo el calor natural del cuerpo, las calles estarían repletas de infinitos «exultos». ${ }^{32}$

3 . $^{\text {a }}$ crítica: que los temascales eran pequeños. A esto responde el galeno mexicano que las estufas alemanas también lo eran y, además, así consumían menos leña en calentarlos.

4. ${ }^{\text {a }}$ crítica: que la repentina mudanza de calor a frío altera con vehemencia. De la Lima responde que si esto sucediera produciría dolor; luego si los bañistas no lo sentían sería porque la alteración no era considerable.

Para el doctor Ambrosio de la Lima, todas estas razones y las autoridades citadas acreditaban la utilidad de las termas y de los temascales, ya que ambas eran una misma cosa, a la vez que también probaban el gran daño y perjuicio que se seguiría de su prohibición, no sólo a los indios sino también a otra muchísima gente que los usaba.

\section{La reglamentación de los temascales públicos}

Ante los informes médicos que ponían de relieve la utilidad de los temascales, el conde de Galve decretó el 9 de noviembre de 1689 que se hiciese conforme proponía el real acuerdo en su parecer de 17 de octubre

31 Secreciones que, después de segregadas, son reabsorbidas por el organismo.

32 Cultismo aplicado en este caso a la calidad de una persona y que se podría traducir como individuo sin energía, aplanada por la falta de «calor natural». 
pasado, comisionando a los oidores Juan Bautista de Urquiola y Fernando de Haro Monterroso la asignación de los doce temascales públicos aceptados. La información en torno a todo lo sucedido respecto a los baños de vapor de origen prehispánico fue enviada por el conde de Galve a Madrid. ${ }^{33}$ Al fiscal del Consejo de Indias le pareció bien lo actuado, aunque dio una serie de prevenciones que, lamentablemente, desconocemos debido a que el soporte documental en que se hallan escritas está tan deteriorado que no permite su lectura. Sean cuales fuesen, el Consejo aprobó lo decretado por el virrey el día 13 de diciembre de 1691. Mientras tanto, en la ciudad de México tuvo lugar el señalamiento de los doce temascales públicos, que no fueron ninguno de los veintidós citados anteriormente.

\section{CUADRO III}

TEMASCALES PÚBLICOS PERMITIDOS EN LA CIUDAD DE MÉXICO EN NOVIEMBRE DE $1689^{34}$

\begin{tabular}{rlll} 
Núm. & \multicolumn{1}{c}{ Dueño } & \multicolumn{1}{c}{ Barrio } & Usuarios \\
\hline 1 & Don José Martínez & Ho & Hombres \\
2 & Doña Ambrosia de los Reyes, viuda & El Carmen & Hombres \\
3 & Doña María Yáñez y su yerno & Santa Cruz & Hombres \\
4 & José de la Barrera & San Hipólito & Hombres \\
5 & Licenciado Baltasar de Céspedes, presbítero & Calle del Águila & Hombres \\
6 & Teresa Guerrero & La Merced & Hombres \\
7 & Matías Vázquez & Belén & Mujeres \\
8 & Capitán Domingo Montaño & Sta. M. ${ }^{\text {a }}$ la Redonda ${ }^{36}$ & Mujeres \\
9 & Don Diego de Andrade & Belén & Mujeres \\
10 & Doña Felipa Guerrero & Curtidores & Mujeres \\
11 & Luis Antonio y M. ${ }^{a}$ de los Reyes, su mujer & Belén & Mujeres \\
12 & María de la Encarnación Mesnía & Rastro & Mujeres
\end{tabular}

33 AGI, México, 58, conde de Galve al rey, México, 7 de diciembre de 1689.

34 AGI, México, 202, orden al alférez José Cumplido para que no se permitiese en los temascales hombres y mujeres juntos ni tampoco hombres juntos al tiempo de bañarse «para excusar y obviar los graves inconvenientes y pecados que juntos hombres y mujeres cometían en ofensa de Dios nuestro señor». Inserta en el testimonio de los méritos del alférez José Cumplido.

35 «El cual por dejación suya y no haber querido continuar en su uso se subrogó en el que tiene y posee el contador Pedro Vidal de Fuentes, que está y cae en la calle que va del Reloj para la de Santa Catarina de Sena».

36 «En casas que llaman del placer, con el baño y lavadero de agua limpia que hay en otra casa». 
A los dueños de estos doce temascales les fueron notificadas las condiciones que debían guardar: no admitir en ellos concurso de gente; cada uno de ellos debía usarse conforme a la asignación de género asignada, pero mientras los hombres entrarían de uno en uno, las mujeres sí podrían hacerlo acompañadas; finalmente, se recalcaba que nunca entraran en un mismo baño hombres y mujeres «para excusar y obviar los graves inconvenientes y pecados que juntos, hombres y mujeres, cometían en ofensa de Dios nuestro señor». ${ }^{37}$ El que contraviniese las normas sería castigado con la demolición de su temascal y doscientos azotes y diez años de obraje si fuera un indio, y diez años de destierro a Filipinas o cualquier otro presidio si era «de otra esfera», y penas iguales para todo aquel que abriese un temascal público sin tener licencia para ello. Por último, se daba a los notificados un plazo de quince días para sacar el permiso para el uso de su respectivo temascal.

Para vigilar que se cumplieran las citadas normas, el conde de Galve nombró al alférez José Cumplido. ${ }^{38}$ Ignoramos las medidas tomadas al efecto por éste, pero sí sabemos que unas dos décadas después las normas acerca de la separación de sexos en los baños no se seguían a rajatabla. Tan es así que constituyó uno de los cargos que Francisco Garzarón hizo a los miembros de la Audiencia mexicana durante la visita que giró a dicha institución entre 1717 y 1721 . Al respecto, la cédula real despachada en Lerma a 13 de diciembre de 1721, especie de ordenanza realizada a partir de los cargos generales dictados por Garzarón contra los citados magistrados y que ordenaba corregir los abusos en la administración de justicia, disponía lo siguiente:

Reconociendo los frecuentes abusos que se experimentan en el uso de los baños y temascales, disimulando entrar en ellos a un mismo tiempo personas de ambos sexos con grave escándalo del cristianismo, os mando castiguéis con el mayor rigor a los bañeros que permiten semejante cosa, y que los alcaldes celen con especial cuidado sobre este punto. ${ }^{39}$

\section{Reflexiones finales}

Tanto en cuanto el pecado constituía en la época estudiada un delito moral, las autoridades habían de perseguir y castigar los «malos usos» de

37 Ibidem.

38 Ibidem.

39 AGI, México, 1081, real cédula, Lerma, 13 de diciembre de 1721. Sobre la visita de Garzarón, véase Alonso, 1988, 11-27. 
los temascales públicos. La propuesta de la sala del crimen de cerrarlos, basada en un informe médico ad hoc, fue desechada por el conde de la Monclova atendiendo a razones de orden público, pues a fines del siglo XVII la antigua costumbre indígena del baño estaba hondamente enraizada en hombres y mujeres de toda clase y condición. Sin atender a estas circunstancias, en Madrid se aprobó su cierre, aunque el conde de Galve actuó más inteligentemente que su antecesor: con nuevos informes médicos esta vez a su favor, permitió los baños privados y autorizó media docena de públicos, mitad para mujeres y mitad para hombres, con la condición de licencia previa de apertura y salvaguardia de la moral en sus instalaciones.

Sobre la propiedad de los temascales públicos la documentación es parca, pero la consulta de los alcaldes del crimen de principios de 1687 nos proporciona un dato relevante aunque impreciso: pertenecían a conventos de monjas - uno tenía nada menos que tres-, frailes, clérigos, caballeros «y otras personas de su posición». Estos propietarios, que se podían ver afectados por el cierre de sus negocios, los arrendaban a todo tipo de gente, como puede comprobarse en los cuadros que hemos elaborado. En el primero aparecen como dueños seis indios, nueve indias, una mestiza, dos mulatas y un español, mientras que en el segundo aparecen cuatro indios, otras tantas indias, una mestiza, un mulato, una mulata, cinco españoles y otras tantas españolas.

¿Quiénes eran los propietarios de los doce únicos baños públicos autorizados y recogidos en el cuadro tercero? La documentación cita sus nombres, entre ellos cinco personas que usan el «don», un presbítero, un capitán y un contador que subrogó el que dejó don José Martínez. ¿Eran todos ellos los verdaderos propietarios o actuaba alguno como testaferro de un tercero? No tenemos respuesta a ello, pero cabe preguntarnos - aunque la documentación consultada no permita contestar tampoco a este interrogante- si la actitud del conde de la Monclova de no oponerse al cierre de los temascales propuesto por la sala del crimen y la posterior de su sucesor el conde de Galve de permitir los privados y autorizar una docena de públicos no obedeció a sendos intentos tanto de evitar el malestar social de las clases populares perjudicadas por el cierre como también de salvaguardar los intereses económicos de algunos de sus propietarios.

Finalmente, la denuncia por sodomía realizada a fines de 1686 o principios del año siguiente permitió a las autoridades, a través del proceso judicial abierto, conocer una serie de actuaciones inmorales que tenían como escenario los baños de la ciudad. Ello no significa que esos «malos usos» no 
existieran con anterioridad a esa fecha y es probable que una revisión de la documentación de archivo proporcione nuevas evidencias al respecto, además de sobre el número de baños de vapor existentes y su funcionamiento en otros momentos de la época colonial. Por lo que respecta al estudio que aquí presentamos, muestra un ejemplo de cómo la extirpación de unas actuaciones consideradas inmorales por las autoridades se topó con los intereses de los usuarios de los baños públicos y probablemente de sus propietarios, a los que se plegaron para evitar males mayores primero el conde de la Monclova y posteriormente su sucesor. No sólo no pudieron ser cerrados en su totalidad sino que, pocos años después, de nuevo fueron denunciados los «malos usos» de los temascales públicos mexicanos.

Recibido el 5 de mayo de 2011 Aceptado 18 de noviembre de 2011

\section{Bibliografía}

Alcina Franch, José: «El temazcal en Mesoamérica: panorama etnográfico», Gades, 20, Cádiz, 1992, 131-161.

Alcina Franch, José: Temazcalli: higiene, terapéutica, obstetricia y ritual en el Nuevo Mundo, Sevilla, Consejo Superior de Investigaciones Científicas, Escuela de Estudios Hispano-Americanos, 2000.

Alonso, María Luz: «La visita de Garzarón a la Audiencia de México: notas para su estudio», en Estudios jurídicos en homenaje al maestro Guillermo Floris Margadant, México, Universidad Nacional Autónoma de México, 1988, 11-27.

Clavero, Bartolomé: «Delito y pecado: noción y escala de transgresiones», en Tomás y Valiente, Francisco et al.: Sexo barroco y otras transgresiones premodernas, Madrid, Alianza Editorial, 1990, 57-89.

Gruzinski, Serge: «Las cenizas del deseo: homosexuales novohispanos a mediados del siglo XVII», en Ortega, Sergio (ed.): De la santidad a la perversión o de por qué no se cumplía la ley de Dios en la sociedad novohispana, México, Grijalbo, 1985, 255-279.

Silva Galeana, Librado: «In Temazcalli: (relato en náhuatl y su traducción al castellano)», Estudios de Cultura Náhuatl, 17, México, 1984, 227-233.

Silva Prada, Natalia: «El uso de los baños temascales en la visión de dos médicos novohispanos: estudio introductorio y transcripción documental de los informes de 1689», Historia Mexicana, 205, LII-1, México, julio-diciembre, 2002, 5-56. 


\section{PATRICIO HIDALGO NUCHERA}

Soustelle, Jacques: La vida cotidiana de los aztecas en víspera de la conquista, México, Fondo de Cultura Económica, 1956.

Viesca, Carlos T.: Medicina prehispánica de México: el conocimiento médico de los nahuas, México, Panorama Editorial, 1986. 